Check for updates

Cite this: RSC Adv., 2017, 7, 25780

Received 28th March 2017

Accepted 4th May 2017

DOI: 10.1039/c7ra03611f

rsc.li/rsc-advances

\section{Intrinsic kinetics study of rosin hydrogenation on a nickel catalyst supported on spent equilibrium catalyst}

\author{
Yingying Huang, ${ }^{a}$ Linlin Wang, (D) *ab Xiaopeng Chen, ${ }^{\text {ab }}$ Xiaojie Wei, ${ }^{\text {ab }}$ Jiezhen Liang ${ }^{\text {ab }}$ \\ and Wei Li ${ }^{\mathrm{a}}$
}

Reaction pathways and intrinsic kinetics of rosin hydrogenation over a spent equilibrium catalyst-supported nickel catalyst were investigated in a batch reactor. Gas chromatography-mass spectrometry (GC-MS) analysis revealed that the reaction pathway of rosin involved isomerization, hydrogenation, and dehydrogenation of various resin acids. In the temperature range between 423 and $453 \mathrm{~K}$ and stirring rates above $500 \mathrm{rpm}$, external and internal mass transfer limitations in catalyst particles with a size of 20-80 $\mu \mathrm{m}$ were eliminated. A power-law model was used to determine the intrinsic kinetic parameters of rosin hydrogenation based on the experimental data. The results showed that reactivity trends of rosin hydrogenation below $453 \mathrm{~K}$ are well-fitted by a pseudo-first-order kinetic model. Activation energies for neoabietic acid isomerization, palustric acid isomerization, abietic acid (AA) partial hydrogenation, AA hydrogenation, AA dehydrogenation, and pimaric acids hydrogenation were 66.60, 58.06, 73.02, 86.67, $107.42,37.60 \mathrm{~kJ} \mathrm{~mol}^{-1}$, respectively.

\section{Introduction}

Rosin is an abundant and renewable raw material obtained by distilling oleoresin from pine trees. It is composed primarily of resin acids with unstable $\mathrm{C}-\mathrm{C}$ double bonds, ${ }^{1}$ which makes it easily oxidized in air and allergenic. Different chemical reactions (hydrogenation, esterification, disproportionation, etc.) have been used to modify rosin for industrial applications. ${ }^{2}$ Compared with non-modified rosin, hydrogenated rosin (HR) has a lighter colour, higher oxygen tolerability, and lower allergenicity. ${ }^{3}$ Because of their excellent features, HR and its derivatives are widely used as an additive and modifier in various applications, especially in pharmaceuticals ${ }^{4}$ and pressure-sensitive adhesives. ${ }^{5,6}$ Because of the steric effect of the tricyclic skeleton structure and the high viscosity, the hydrogenation reaction of rosin is usually performed at high temperatures $\left(200-270{ }^{\circ} \mathrm{C}\right)$, high $\mathrm{H}_{2}$ pressure, or high catalyst mass over a precious metal ( $\mathrm{Pd}, \mathrm{Ru}, \mathrm{Rh}$, charcoal support), $\mathrm{NiMo} / \mathrm{Al}_{2} \mathrm{O}_{3}, \mathrm{Ni}-\mathrm{Y}$ zeolite, or ammonium tetrathiomolybdate catalyst. $^{7-9} \mathrm{Pd} / \mathrm{C}$ has been regarded as the best catalyst for the hydrogenation reaction of rosin, but it has the common disadvantages of noble metal catalysts including high cost and limited availability.

${ }^{a}$ School of Chemistry and Chemical Engineering, Guangxi University, Nanning 530004, PR China. E-mail:wanglinlin1971@sina.com

${ }^{b}$ Guangxi Key Laboratory of Petrochemical Resources Processing and Process Intensification Technology, Guangxi University, Nanning 53004, PR China
Fluid catalytic cracking (FCC) is an important industrial operation in the refining industry, in which heavy hydrocarbons are converted to products with lower molecular weight. The catalyst used in FCC process is generally composed of Y zeolite, a silica-alumina matrix, and binder. ${ }^{10}$ During the FCC operation, part of the equilibrium catalyst will lose its activity and need to be removed from the reactor. The spent equilibrium catalyst (denoted as Scat) mainly consists of $\mathrm{Al}_{2} \mathrm{O}_{3}, \mathrm{SiO}_{2}$, and a few heavy metals (Fe, Ni, Co). ${ }^{11}$ Most of the Scat is solidified and disposed of as landfill; however, it may pollute of soil and water with heavy metals.

Recently, a potential use of Scat as a catalyst support material was suggested. Vasireddy et al. ${ }^{12}$ used Scat as the support material to synthesize an Fe-based catalyst, and their results showed that Scat can improve the attrition resistance of the catalyst. Our group prepared a Scat-supported $\mathrm{Ni}$ catalyst by solution impregnation and used it to catalyze the conversion of pinenes to pinane. ${ }^{13}$ An in situ synthesis method of layered double hydroxides (LDHs) has been used to synthesize a Scatsupported $\mathrm{Ni}$ catalyst. ${ }^{14}$ LDHs contain positively charged brucite-like layers and an anion interlayer. ${ }^{15}$ By changing the compositions of the layers and anions, LDHs can show different properties. LDHs have been used in many reactions, such as oxygen evolution, ${ }^{16}$ water spitting, ${ }^{17}$ and hydrogenation. ${ }^{18} \mathrm{We}$ have used Scat as not only a support but also an $\mathrm{Al}^{3+}$ source to synthesize an $\mathrm{LDH}-\mathrm{Ni} / \mathrm{Scat}$ catalyst with $\mathrm{NO}_{3}{ }^{2-}$ as interlayer anion. ${ }^{14,19}$ The LDH-Ni/Scat catalyst exhibited excellent activity and long lifetime in rosin hydrogenation, indicating the potential of this catalyst for industrial application. In this 
paper, we obtain more detailed information on the rate of rosin hydrogenation over the $\mathrm{LDH}-\mathrm{Ni} / \mathrm{Scat}$ catalyst, examine the catalytic reaction pathways of rosin, and investigate the kinetics of rosin hydrogenation over the $\mathrm{LDH}-\mathrm{Ni} / \mathrm{Scat}$ catalyst in a stainless-steel batch reactor. This study also presents the development of large-scale solid waste as catalyst materials.

\section{Materials and methods}

\subsection{Materials}

Rosin (technical grade) containing $\sim 80 \%$ of abietic acid (AA) was kindly supplied by Guangxi Nanning Heli Pine Ltd., China. Solvent oil (Oil \#200) with a melting point of $-180.5 \mathrm{~K}$, boiling point of $340.5 \mathrm{~K}$, density of $0.75-0.78 \mathrm{~kg} \mathrm{~m} \mathrm{~m}^{-3}$, and relative density of $0.65-0.70 \mathrm{~g} \mathrm{~cm}^{-3}$ was purchased from HeLiShi Petroleum \& Chemical Technology Development Co., Ltd., China. Aqueous tetramethylammonium hydroxide (TMAH) for gas chromatography was purchased from Sigma-Aldrich Shanghai Trading Co Ltd., Shanghai, China. $\mathrm{Ni}\left(\mathrm{NO}_{3}\right)_{2} \cdot 6 \mathrm{H}_{2} \mathrm{O}$, $\mathrm{NH}_{4} \mathrm{NO}_{3}$, and $\mathrm{NH}_{3} \cdot \mathrm{H}_{2} \mathrm{O}$ were all of A.R. grade. Scat powder with an average particle size of $20-80 \mu \mathrm{m}$ was supplied by CNPC Guangxi Tiandong Petrochemical Co., Ltd., China. The main components of the Scat are listed in Table 1. The deionized water used in all experiments had a conductivity of less than $10^{-6} \mathrm{~S} \mathrm{~cm}^{-1}$. Ultra-high-purity $\mathrm{H}_{2}$ gas (99.999\%, AGA, Nanning Lantian Experiment Equipment Co., Ltd., Guangxi, China) was used without further purification. The Ni metal dispersion before reaction of the $\mathrm{LDH}-\mathrm{Ni} / \mathrm{Scat}$ sample measured by hydrogen chemisorption using a Micromeritics Chemisorb 2720 was $11 \%$.

\subsection{Synthesis of the Scat-supported Ni catalyst}

As described in ref. 14, $\mathrm{Ni}\left(\mathrm{NO}_{3}\right)_{2} \cdot 6 \mathrm{H}_{2} \mathrm{O}$ and $\mathrm{NH}_{4} \mathrm{NO}_{3}$ with a molar ratio of $2: 1$ were dissolved in deionized water to make a mixed salt solution. The solution and Scat were added to a four-necked flask stirred at a rate of $200 \mathrm{rpm}$ in a water bath at 313 K. Ammonia (4\%) was used to keep pH of the system neutral. The in situ synthesis process was conducted for $12 \mathrm{~h}$. The precipitate was centrifuged and thoroughly washed with deionized water. The final NiAl-LDH precursor (PLDH-Ni/Scat) was obtained after drying at $343 \mathrm{~K}$ for $6 \mathrm{~h}$. After calcination and reduction, a $\mathrm{LDH}-\mathrm{Ni} / \mathrm{Scat}$ sample was obtained and stored in Oil \#200 until use in rosin hydrogenation.

\subsection{Catalyst characterization}

The average pore diameter, pore volume, and BrunauerEmmett-Teller (BET) surface area of Scat, PLDH-Ni/Scat and LDH-Ni/Scat samples were measured by a Micromeritics Gemini VII 2390 analyzer at $77 \mathrm{~K}$ using the volumetric method. Sample structures were determined using X-ray diffraction

Table 1 Main components of Scat powder

$\begin{array}{lllllllllll}\text { Elements } & \mathrm{Al} & \mathrm{Si} & \mathrm{Sb} & \mathrm{Ni} & \mathrm{V} & \mathrm{Fe} & \mathrm{Ca} & \mathrm{Ti} & \mathrm{Zn} & \mathrm{Cr}\end{array}$
$\begin{array}{lllllllllll}\text { Content (\%) } & 33.9 & 29.1 & 13.0 & 9.9 & 4.2 & 2.9 & 2.1 & 1.5 & 1.4 & 0.8\end{array}$
(XRD) with $\mathrm{Cu} \mathrm{K} \alpha$ radiation $(\gamma=1.54 \AA)$ at $45 \mathrm{kV}$ and $40 \mathrm{~mA}$ (Shimadzu XRD-600). Morphology characterization was carried out using a scanning electron microscope (SEM, S-3400N, Hitachi High Technologies Co., Tokyo, Japan) and a fieldemission transmission electron microscope (TEM, FEI Tecnai G2 F30). The particle size of $\mathrm{LDH}-\mathrm{Ni} / \mathrm{Scat}$ was analyzed by BT1800 Dynamic Image Particle Size \& Shape Analysis System, Bettersize instruments Ltd., Dandong, China.

\subsection{Rosin hydrogenation}

All reactions were performed in a 2 L stirred stainless steel reactor (Dalian Tongchan Autoclave Vessel Manufacturing Co., Ltd., China) equipped with a stirrer, temperature controller, and sample tube with a diameter of $5 \mathrm{~mm}$. A steel filter with a bore diameter less than $10 \mu \mathrm{m}$ was installed on the bottom of the sample tube to filter the catalyst powders. The experiment device schematic diagram is shown in Fig. 1. Even though rosin was diluted by Oil \#200, the mixed solution still had high viscosity and tended to be coagulated at low temperature. In addition, all the reactions were performed under high $\mathrm{H}_{2}$ pressure, which made the sampling operation difficult and dangerous. To keep the rosin solution flow and sample tube clean, the sample tube was covered by electrical heating belts and connected to the hydrogen tube. For security, all the threeway valves in the heating zone were closed. When sampling, the three-way valves of the sample tube were opened, the solution sample was withdrawn, and then the valves were closed. A typical reaction was described in ref. 14. Certain amounts of rosin (ground to a size of $10 \mathrm{~mm}$ ), Oil \#200, and LDH-Ni/Scat were added to the reactor. The catalyst dosage was $5 \mathrm{wt} \%$. The reactor was closed and connected to a vacuum system to remove the air. $\mathrm{N}_{2}$ gas was charged into the reactor to a pressure of 0.5 MPa, which was maintained for several minutes to check its gas-tightness. Then $\mathrm{N}_{2}$ gas was replaced by $\mathrm{H}_{2}$ gas. The stirrer and temperature controller were turned on. Once the temperature reached the desired value, the stirring rate and $\mathrm{H}_{2}$ pressure were increased to initiate the hydrogenation reactions. The present investigation was carried out at temperatures of 423, 433,443 , and $453 \mathrm{~K}$ under an $\mathrm{H}_{2}$ pressure of $5 \mathrm{MPa}$.

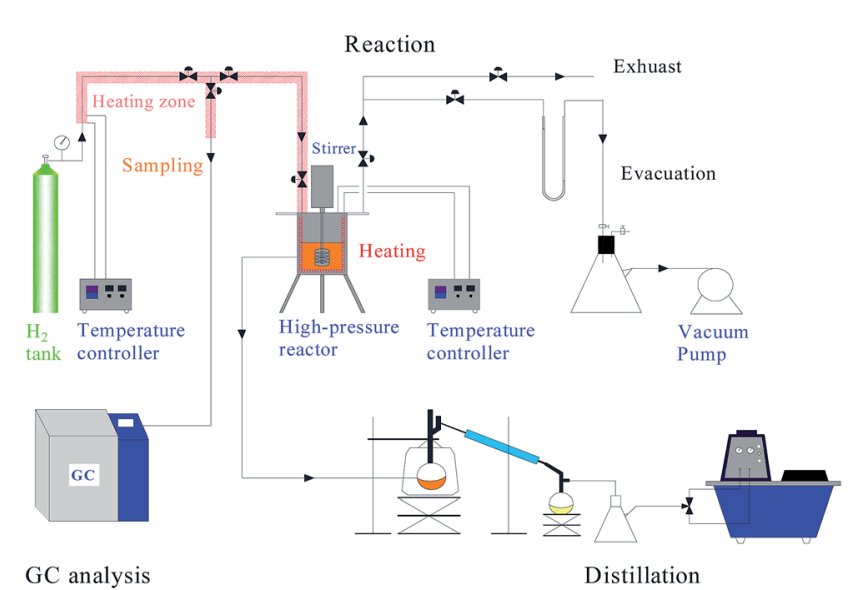

Fig. 1 Schematic of the experimental setup. 


\subsection{Sample analysis}

Liquid-phase samples were taken from the reactor after $0,1,3,5$, $10,15,20,25,30,40,60,80$, and $100 \mathrm{~min}$ of hydrogenation. Before analysis, the reaction species in each sample were methylated with 4\% TMAH solution (details in ASTM Standard D 2010). The methylated samples were qualitatively analysed by gas chromatography-mass spectrometry (GC-MS) using a system that coupled an HP 6890 gas chromatograph with an HP 5973 mass selective detector (Agilent Technologies) and an HP-5MS silica column $(30 \mathrm{~m}$ long $\times 0.25 \mathrm{~mm}$ i.d. $\times 0.25 \mu \mathrm{m}$ film thickness, Agilent, USA). The temperature program of the GC-MS was as follows: initial column temperature, $433 \mathrm{~K}$; heat at $5 \mathrm{~K} \mathrm{~min}^{-1}$ to $493 \mathrm{~K}$, at $1 \mathrm{~K} \mathrm{~min}^{-1}$ to $513 \mathrm{~K}$, then at $5 \mathrm{~K} \mathrm{~min}^{-1}$ to $533 \mathrm{~K}$ and maintained for $3 \mathrm{~min}$. The amount of methylated sample injected into GC-MS was $0.4 \mu \mathrm{L}$. The carrier gas was He with a flow rate of $1.0 \mathrm{~mL} \mathrm{~min}^{-1}$ and the voltage of electron impact ionization was $70 \mathrm{eV}$. A 7890B GC with a fused silica capillary column coated with DB-5 (30 $\mathrm{m} \times 0.25 \mathrm{~mm}$ i.d. $\times 0.25 \mu \mathrm{m}$ film thickness $)$ and a flame ionization detector were also used to trace the hydrogenation reaction of rosin. The temperature program was the same as that of GC-MS. $\mathrm{N}_{2}$ was used as the carrier gas with a flow rate of $60 \mathrm{~mL}$ $\min ^{-1}$ and the pressure before the column was $0.06 \mathrm{MPa}$. The flow rates of air and $\mathrm{H}_{2}$ were 300 and $30 \mathrm{~mL} \mathrm{~min}^{-1}$, respectively.

The mass fraction of each component was obtained by quantitative analysis using GC-MS. The mass fraction was converted into molar concentration through the following mass balance equation:

$$
C_{\mathrm{i}}=\frac{\omega \times G \times d}{M_{\mathrm{i}} \times W} \times 1000
$$

where $C_{\mathrm{i}}$ is the concentration of compound $\mathrm{i}, \mathrm{mol} \mathrm{L}^{-1} ; \omega$ is the mass fraction, \%; $G$ is the mass of hydrogenated rosin, $g$; $d$ is the density of product liquid, $\mathrm{g} \mathrm{cm}^{-3} ; M$ is the molecular weight, $\mathrm{g}$ $\mathrm{mol}^{-1}$; and $W$ is the mass of product liquid, $\mathrm{g}$.

\section{Results and discussion}

\subsection{Catalyst characterization}

Fig. 2 shows the XRD patterns of Scat, PLDH-Ni/Scat, and LDH$\mathrm{Ni} /$ Scat. All the samples show the same peaks at $2 \theta=36.5^{\circ}$,

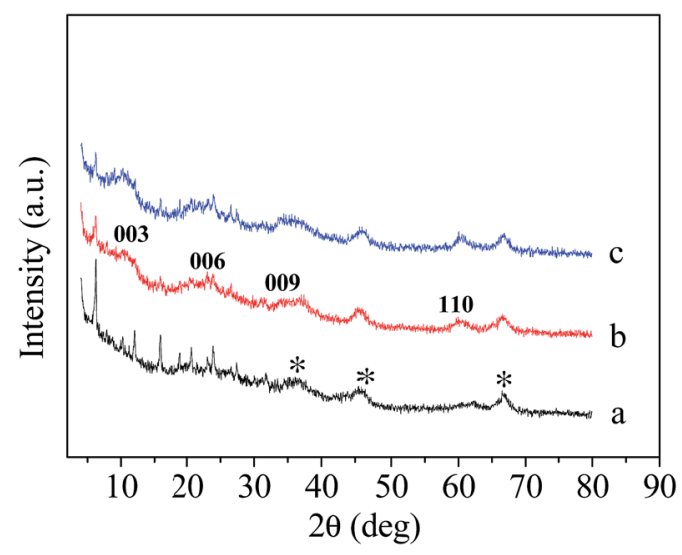

Fig. 2 XRD patterns of (a) Scat, (b) PLDH-Ni/Scat and (c) LDH-Ni/Scat. $45.6^{\circ}$, and $66.6^{\circ}$, which originate from $\gamma-\mathrm{Al}_{2} \mathrm{O}_{3} \cdot{ }^{20} \mathrm{PLDH}-\mathrm{Ni} / \mathrm{Scat}$ has visible peaks at $10.5^{\circ}, 20.8^{\circ}, 34.1^{\circ}$, and $60.1^{\circ}$, corresponding to the 003, 006, 009, and 110 crystal faces of $\mathrm{LDH}$, respectively. ${ }^{21}$ This proves that the NiAl-LDH structure successfully grew on the surface of the Scat support. The target catalyst was obtained by calcination of PLDH-Ni/Scat at $723 \mathrm{~K}$ and reduction under $20 \mathrm{~min} \mathrm{~L}^{-1}$ of $\mathrm{H}_{2}$ for $2.5 \mathrm{~h}$. The characteristic peaks of the LDH structure were still maintained in the XRD pattern of LDH$\mathrm{Ni}$ /Scat but those of nickel did not appear, meaning that the LDH structure did not collapse even at a high temperature. This may be the reason why the $\mathrm{LDH}-\mathrm{Ni} / \mathrm{Scat}$ sample can retain a uniform surface, as shown later in the SEM analysis. In addition, the broad weak diffraction peaks of the samples indicate their low crystallinity or small particle size (or both), ${ }^{22}$ both of which could also result in a high dispersion of $\mathrm{Ni}$ particles.

The textures of Scat, PLDH-Ni/Scat and LDH-Ni/Scat were tested by $\mathrm{N}_{2}$ adsorption-stripping and their surface areas were calculated using the BET method. Morphological data are listed in Table 2. According to the relationship between the average pore diameter and pore volume, it can be conjectured that the narrow channels in PLDH-Ni/Scat are smaller than that in the support. This phenomenon suggests that the LDH has grown in the pore of Scat and blocked some pores. After calcination and reduction, the average pore diameter and pore volume of LDH-Ni/Scat were the same as those of PLDH-Ni/ Scat, but the BET surface area decreased. This may be caused by the migration and aggregation of the active particle during reduction process.

The micro-morphology of LDH-Ni/Scat was observed by TEM, as shown in Fig. 3a and b. The TEM image in Fig. 3a indicates that the Scat support was composed of several irregular stacked blocks that formed an amorphous and porous structure, confirmed by the wide peaks in Fig. 2a. Fig. $3 \mathrm{~b}$ reveals that the Ni particles (black points in images) in LDH-Ni/Scat were extremely small (3-7 nm) and the dispersion of active components on $\mathrm{LDH}-\mathrm{Ni} / \mathrm{Scat}$ was uniform, agreeing well with the XRD results. SEM images of Scat and LDH-Ni/Scat are shown in Fig. $3 c$ and d, respectively. The Scat sample processes an amorphous structure with some $\mathrm{Al}_{2} \mathrm{O}_{3}$ particles (Fig. 3c). Meanwhile, LDH-Ni/Scat has a uniform netlike structure distributed homogeneously throughout the Scat particulate. An interconnected network was constructed between the LDH and Scat support, which formed a strong connection between the active component and support. The macrospores in the $\mathrm{LDH}-\mathrm{Ni} / \mathrm{Scat}$ catalyst may provide abundant reaction sites for hydrogenation and enhance gas-liquid mass transfer.

Table 2 Structural data for Scat, PLDH-Ni/Scat, and LDH-Ni/Scat

\begin{tabular}{llll}
\hline Sample & $\begin{array}{l}\text { Average pore } \\
\text { diameter }(\mathrm{nm})\end{array}$ & $\begin{array}{l}\text { Pore volume } \\
\left(\mathrm{cm}^{3} \mathrm{~g}^{-1}\right)\end{array}$ & $\begin{array}{l}\text { BET surface } \\
\text { area }\left(\mathrm{m}^{2} \mathrm{~g}^{-1}\right)\end{array}$ \\
\hline Scat & 3.75 & 0.14 & 41.60 \\
PLDH-Ni/Scat & 3.93 & 0.13 & 94.01 \\
LDH-Ni/Scat & 3.93 & 0.13 & 83.77
\end{tabular}




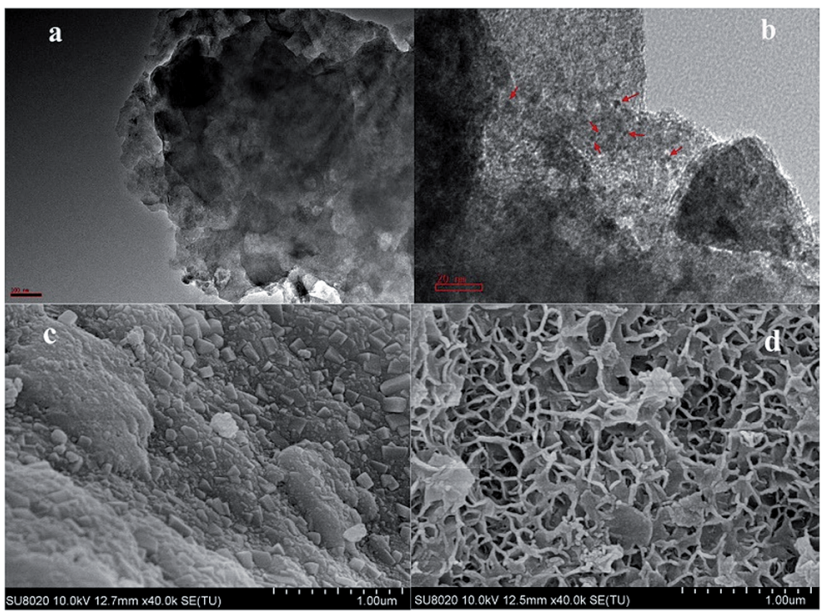

Fig. 3 TEM images of LDH-Ni/Scat with scale bars of (a) $100 \mathrm{~nm}$ and (b) $20 \mathrm{~nm}$. SEM images of (c) Scat and (d) LDH-Ni/Scat.

\subsection{Different catalysts for rosin hydrogenation}

To investigate the catalytic activity of the as-synthesized catalyst, we performed the rosin hydrogenation over $\mathrm{Pd} / \mathrm{C}$, unsupported Scat, and LDH-Ni/Scat catalyst under the same reaction conditions. The results were listed in Table 3. As compared to $\mathrm{Pd} / \mathrm{C}$ catalyst in Table 3, LDH-Ni/Scat catalyst presented a similar result. Even though the dosage of $\mathrm{Pd} / \mathrm{C}$ catalyst was less than that of $\mathrm{LDH}-\mathrm{Ni} / \mathrm{Scat}$, it is worth to notice that noble metal palladium is much expensive than transition metal nickel. Considering the use of Scat, LDH-Ni/Scat is a costeffective and environmental friendly catalyst that can be used in the rosin hydrogenation. Unsupported Scat shows extremely low activity with a AA conversion as low as $13.56 \%$, due to the less exposed catalytically active sites.

\subsection{Reaction process analysis}

Rosins from different sources have different compositions, but they all consist of abietic acids (AAs), pimaric acids (PIAs), and a small amount of neutral components. ${ }^{23}$ AAs and PIAs are isomers with a formula of $\mathrm{C}_{20} \mathrm{H}_{30} \mathrm{O}_{2}$. While the former has conjugated $\mathrm{C}=\mathrm{C}$ double bonds, the latter do not. AAs include $\mathrm{AA}$, neoabietic acid (NEA), and palustric acid (PAA); while PIAs can be divided into pimaric acid (PIA), isopimaric acid (ISA), and sandaracopimaric acid (SAA). The major component of the rosin we used was analyzed by GC-MS; the results are presented in Table 4 .

Table 3 Comparison of the results of $\mathrm{Pd} / \mathrm{C}$, Scat, and LDH-Ni/Scat for rosin hydrogenation ${ }^{a}$

\begin{tabular}{lll}
\hline Catalyst & $\begin{array}{l}\text { Dosage } \\
(\text { wt\% })\end{array}$ & $\begin{array}{l}\text { AA conversion } \\
(\%)\end{array}$ \\
\hline Pd/C & 0.2 & 87.47 \\
Scat & 5 & 13.56 \\
LDH-Ni/Scat & 5 & 88.69
\end{tabular}

${ }^{a}$ Reaction conditions: $433 \mathrm{~K}, 5 \mathrm{MPa}, 350 \mathrm{~g}$ rosin, $350 \mathrm{~g}$ Oil \#200, $60 \mathrm{~min}$, $600 \mathrm{rpm}$ stirring rate.
Table 4 Compositions of rosin

\begin{tabular}{llllllll}
\hline Component & AA & PAA & NEA & PIA & ISA & SAA & DEA \\
Content (\%) & 49.1 & 16.6 & 13.9 & 7.0 & 1.7 & 1.2 & 3.6 \\
\hline
\end{tabular}

Wang et al. ${ }^{24}$ and Souto et al. ${ }^{25}$ have discussed the pathway of rosin disproportionation over commercial $\mathrm{Pd} / \mathrm{C}$ catalyst. In their papers, reactions were performed at temperatures from 483 to $533 \mathrm{~K}$ and 473 to $513 \mathrm{~K}$, respectively, using $0.1 \% \mathrm{Pd} / \mathrm{C}$ catalyst under the protection of $\mathrm{N}_{2}$ gas. They observed that rosin disproportionation involves dehydrogenation, hydrogenation and isomerization reactions and the dehydrogenation of AA was the main reaction under the reaction conditions. In our work, those three kinds of reactions were also identified in the catalytic rosin hydrogenation process. The reaction framework of rosin hydrogenation over LDH-Ni/Scat catalyst is illustrated in Fig. 4.

The concentrations of different components over time were traced by GC-MS. During the catalytic hydrogenation of rosin over the LDH-Ni/Scat catalyst, the amounts of AA and PIAs decreased rapidly while those of dihydroabietic acid (DIA), tetrahydroabietic acid (TEA), DEA, and dihydropimatic acids (DPIAs) increased. During heating at $473 \mathrm{~K}$ or higher, AA, NEA, and PAA can isomerize to each other and form a mixture with $>80 \%$ AA. ${ }^{26}$ However, the concentrations of AA, NEA, PAA did not increase during the reaction. This is because the presence of $\mathrm{H}_{2}$ and LDH-Ni/Scat rapidly induces AA hydrogenation. NEA and PAA isomerized to AA, which was immediately hydrogenated to DIA and TEA, as shown in Fig. 4. At the same time, AA was converted to DEA through loss of hydrogen atoms. PIAs were hydrogenated to DPIAs because their $\mathrm{C}=\mathrm{C}$ extended into a cyclic structure is prone to hydrogenation. ${ }^{25}$ The GC-MS results showed that the DPIAs were a mixture of 8-pimarenoic acid and 14-pimarenoic acid, in agreement with a previous report. ${ }^{27}$ The online GC-MS analysis revealed that DIA and TEA were generated at the same time, so a parallel reaction pathway was proposed, as outlined in Fig. 4. The main difference between rosin hydrogenation and rosin disproportionation is that in rosin hydrogenation, the hydrogenation of AA is the main reaction, AA transforms to DIA and TEA, and the dehydrogenation of AA is very slight; while in rosin disproportionation, DEA is the main product.

\subsection{Mass transfer analysis}

Catalytic hydrogenation of rosin over the LDH-Ni/Scat catalyst is a gas-liquid-solid three-phase reaction involving $\mathrm{H}_{2}$ gas, a mixed of rosin and HR, and the solid catalyst. The reaction process can be divided into several physical and chemical steps: $^{28}$ (i) $\mathrm{H}_{2}$ diffusion from the gas phase into the rosin solution; (ii) mass transfer of resin acids and $\mathrm{H}_{2}$ from solution to the catalyst surface; (iii) reactant transfer from the surface into the pores of the catalyst; (iv) chemical reaction at the catalyst active site; (v) product desorption from the active site; (vi) product transfer from the catalyst pore to surface; (vii) product transfer from the catalyst surface to solution. Reactant diffusion through the boundary later around the catalyst is an external 


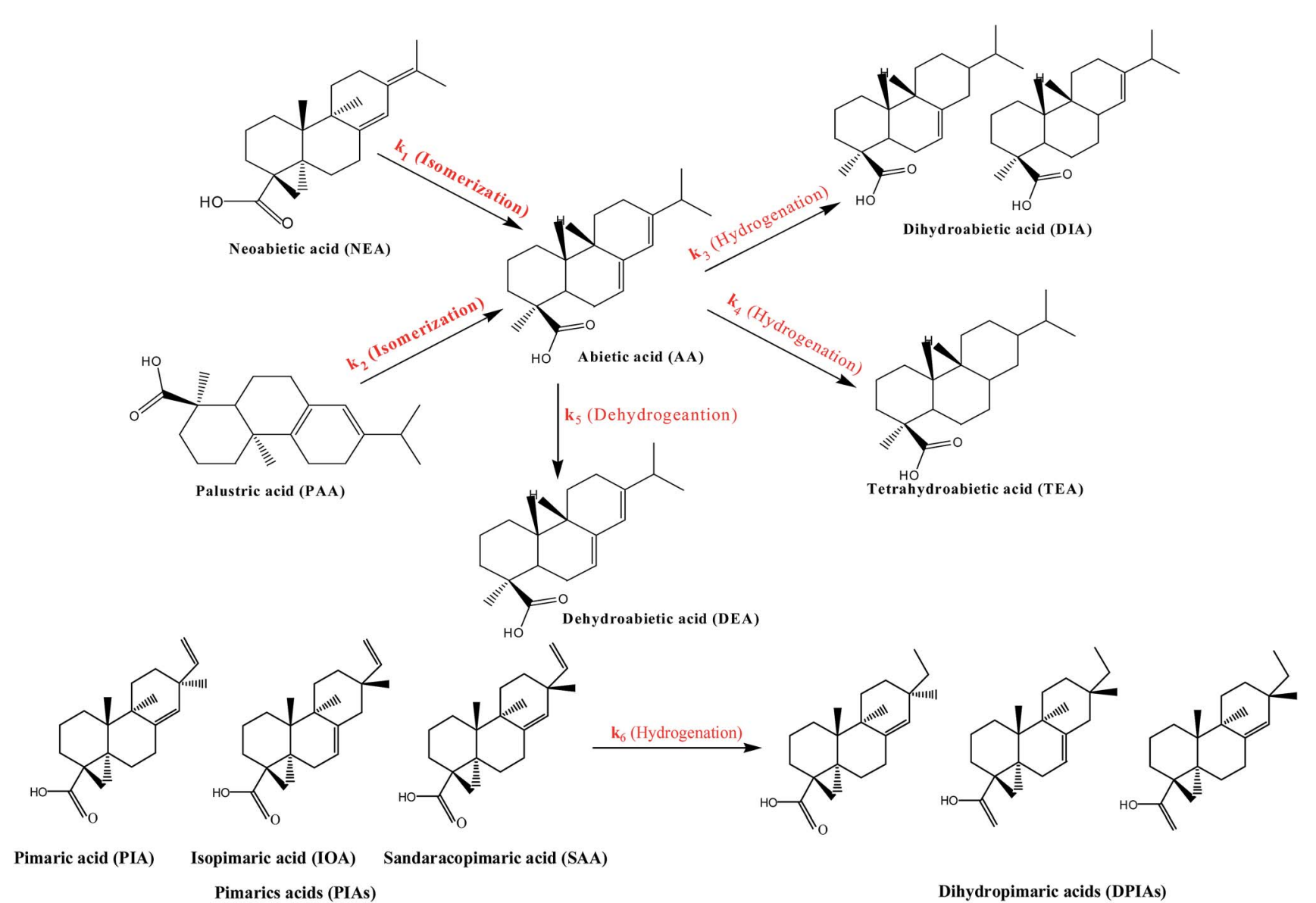

Fig. 4 Reaction network involved in the hydrogenation of gum rosin.

diffusion process, while transfer from the surface of the catalyst into the pores is an internal diffusion process.

The effect of external diffusion on catalytic reaction can be checked by performing the reaction at various stirring rates. ${ }^{29}$ External diffusion can be eliminated when the stirring rate is high enough. Fig. 5a presents the rosin hydrogenation results over LDH-Ni/Scat at stirring rates from 300 to $700 \mathrm{rpm}$.

With increasing stirring rate, the rate of AA conversion first increased, and then became stable. When the stirring rate exceeded $500 \mathrm{rpm}$, the maximum rate of AA conversion was reached, and it showed no obvious dependence on stirring rate. Therefore, in the present investigation, the effect of external diffusion on rosin hydrogenation could be eliminated by using a stirring rate of $600 \mathrm{rpm}$.

$\mathrm{LDH}-\mathrm{Ni} / \mathrm{Scat}$ is a porous material with a high surface area of $83.77 \mathrm{~m}^{2} \mathrm{~g}^{-1}$ and contains abundant pores, as shown in Table 2 and Fig. 3d because most of the catalytically active sites are located in the pore network, internal mass transfer plays a very important role in the catalytic process. ${ }^{30}$ The internal mass transfer resistance can be evaluated by conducting reactions under identical conditions with catalysts of different particle sizes or estimating the Weisz-Prater criterion $\left(C_{\mathrm{W}-\mathrm{P}}\right){ }^{31}$ The classical strategy was used to examine the internal transfer by performing the reaction over LDH-Ni/Scat with different particle sizes. The LDH-Ni/Scat catalyst was sieved to collect the catalyst particles of $20-50$ and $50-80 \mu \mathrm{m}$. Fig. $5 \mathrm{~b}$ shows the particle sizes of catalyst have no obvious effect on the AA conversion, meaning that the internal transfer can be eliminated in the above range of particle size. This will be proved by the following calculation. In this paper, within the catalyst pellet, the influence of internal diffusion resistance on each reactant was characterized by $C_{\mathrm{W}-\mathrm{P}},{ }^{32}$

$$
C_{\mathrm{W}-\mathrm{P}}=\frac{r_{0} \times R_{\mathrm{p}}^{2}}{C_{\mathrm{s}} \times D_{\text {eff }}} \leq 0.3
$$

where $r_{0}$ is the initial reaction rate, $\mathrm{mol} \mathrm{m} \mathrm{m}^{-3}$ cat $\mathrm{s} ; R_{\mathrm{p}}$ is the radius of a catalyst particle, $\mathrm{m}$; $C_{\mathrm{s}}$ is the concentration of the component at the catalyst surface, $\mathrm{mol} \mathrm{m}^{-3}$; and the effective diffusivity $D_{\text {eff }}=\varepsilon D_{\mathrm{j}}$, where $\varepsilon$ is the support porosity $(0.6$ for the Scat used) and $D_{\mathrm{j}}$ is the diffusivity of the component in liquid estimated using the Wilke-Chang equation (eqn (3)), ${ }^{33} \mathrm{~cm}^{2} \mathrm{~s}^{-1}$.

$$
D_{\mathrm{j}}=5.4 \times 10^{-8}\left(\frac{M_{\mathrm{s}}^{1.2} L_{\mathrm{s}}{ }^{1.3} T}{\eta V_{\mathrm{m}}^{0.5} L^{0.3}}\right)
$$

where $M_{\mathrm{S}}$ is the molecular weight of the solvent (Oil \#200 is composed of C4-C11 alkanes; the biggest value of $156 \mathrm{~g} \mathrm{~mol}^{-1}$ for $\mathrm{C}_{11} \mathrm{H}_{24}$ was used here); $L_{\mathrm{s}}$ is the latent heat of vaporization of Oil $\# 200$, which is $81 \mathrm{cal} \mathrm{g}^{-1} ; \eta$ is the viscosity of Oil $\# 200,6.31$ $\mathrm{cP}^{34} V_{\mathrm{m}}$ is the molecular volume of the reactant, $\mathrm{cm}^{3} \mathrm{~mol}^{-1}$; and $L$ is the latent heat of vaporization of the reactant, cal $\mathrm{g}^{-1}$. The 


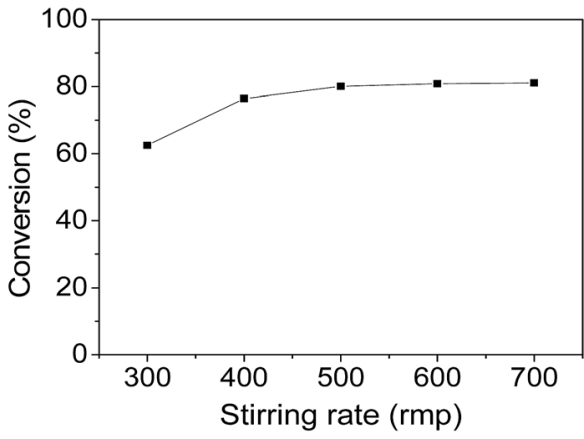

(a)

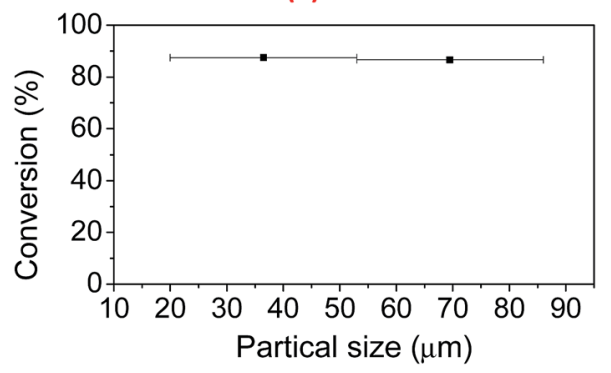

(b)

Fig. 5 Effect of (a) stirrer rate and (b) of catalyst particle sizes on the conversion of AA. Reaction conditions for (a): $190{ }^{\circ} \mathrm{C}, 5 \mathrm{MPa}, 30 \mathrm{~min}$, $17.5 \mathrm{~g}$ catalyst, $350 \mathrm{~g}$ rosin. Reaction conditions for (b): $170{ }^{\circ} \mathrm{C}, 5 \mathrm{MPa}$, 60 min, $17.5 \mathrm{~g}$ catalyst, $350 \mathrm{~g}$ rosin, $350 \mathrm{~g}$ Oil \#200, 600 rpm stirring rate.

particle size of $\mathrm{LDH}-\mathrm{Ni} / \mathrm{Scat}$ was between 20 and $80 \mu \mathrm{m}$ according to the particle analysis, so $R_{\mathrm{p}}$ was set at $40 \mu \mathrm{m}$ (the worst-case scenario).

Because the external diffusion effect has been eliminated, $C_{\mathrm{s}}$ is equal to the bulk concentration of the reactant. Here, $C_{\mathrm{S}}$ was considered as the initial concentration of $\mathrm{AA}\left(C_{\mathrm{A} 0}\right)$ because $\mathrm{AA}$ is the main component of rosin. Initial rates were obtained from the experimental data. $C_{\mathrm{W}-\mathrm{P}}$ values for AA at $423-453 \mathrm{~K}$ are listed in Table 5. The Weisz-Prater number of AA in rosin hydrogenation over $\mathrm{LDH}-\mathrm{Ni} / \mathrm{Scat}$ is $0.003-0.01$, which indicates that the mass-transport resistance within the LDH-Ni/Scat catalyst can be neglected.

\subsection{Kinetic modelling analysis}

Based on the above discussion, mass transfer dose not markedly influence the rate of resin acids conversion at $600 \mathrm{rpm}$. Thus, the conversion rate under the presented conditions represents the intrinsic reaction kinetics for rosin hydrogenation.

Table 5 Assessment of the Weisz-Prater criterion for $\mathrm{AA}^{a}$

\begin{tabular}{lllll}
\hline & $C_{\mathrm{A} 0}, \mathrm{~mol} \mathrm{~L}^{-1}$ & $r_{0}, \mathrm{~mol} \mathrm{~L}^{-1} \mathrm{~min}^{-1}$ & $D_{\mathrm{eff}}, \mathrm{m}^{2} \mathrm{~s}^{-1}$ & $C_{\mathrm{W}-\mathrm{P}}$ \\
\hline 423 & 0.7147 & 0.0051 & $6.21 \times 10^{-11}$ & 0.0031 \\
433 & 0.7118 & 0.0110 & $6.21 \times 10^{-11}$ & 0.0066 \\
443 & 0.7125 & 0.0178 & $6.48 \times 10^{-10}$ & 0.0103 \\
453 & 0.7031 & 0.0188 & $3.97 \times 10^{-10}$ & 0.0108 \\
${ }^{a} M_{\mathrm{s}}=156 ; L_{200 \#}=71-81 \mathrm{cal} \mathrm{g}^{-1} ; \eta_{200 \#}=6.31 \mathrm{cSt} ; V_{\mathrm{mA}}=284.5 \mathrm{~cm}^{3}$ \\
$\mathrm{~mol}^{-1} ; L_{\mathrm{A}}=58.4 \mathrm{cal} \mathrm{g}^{-1} ; R_{\mathrm{p}}=4 \times 10^{-5} \mathrm{~m}$.
\end{tabular}

Kinetic modelling analysis is necessary to propose a model to describe the relationship between reaction rate and reactant concentration. There are two main models, the pseudohomogeneous (PH) and heterogeneous models, commonly used to describe catalytic reactions in different reactors. ${ }^{35-37}$ The $\mathrm{PH}$ model does not take into account the transfer of mass and heat between the liquid and solid phases. Thus, the $\mathrm{PH}$ model is simpler than heterogeneous model and has been widely used in industry. The $\mathrm{PH}$ model has been successfully applied to hydrogenation of acetophenone $\mathrm{e}^{38}$ and the disproportionation of rosin. ${ }^{24}$

In this work, we develop a simplified kinetic model to describe the catalytic hydrogenation of rosin over the $\mathrm{LDH}-\mathrm{Ni} / \mathrm{Scat}$ catalyst. Considering that the rosin solution can be treated as a homogeneous liquid phase and mass transport has been neglected, a PH dynamic model was used to correlate the hydrogenation of rosin in the presence of the LDH-Ni/Scat catalyst. The rate of hydrogenation of the $\mathrm{C}=\mathrm{C}$ bond is a function of resin acid concentration because of $\mathrm{H}_{2}$ excess ( $5 \mathrm{MPa}$ ) used in our work. Chen et al. ${ }^{39}$ studied the hydrogen solubility in rosin-Oil \#200 solution using a same reactor. The $\mathrm{H}_{2}$ concentration $\mathrm{C}^{*}$ in the rosin-Oil \#200 solution can be calculated by

$$
C^{*}=P \cdot 0.0526 \exp (-572.25 / T)
$$

where $P$ and $T$ are the $\mathrm{H}_{2}$ pressure in the reactor and the reaction temperature, respectively. Under $\mathrm{a}_{2}$ pressure of $5 \mathrm{MPa}$, the hydrogen concentrations in rosin-Oil \#200 solution at 423, 433,443 , and $453 \mathrm{~K}$ were $0.068,0.070,0.072$, and $0.074 \mathrm{~mol} \mathrm{~L}^{-1}$, respectively. Since $\mathrm{H}_{2}$ solubility in rosin-Oil \#200 is relatively small, it is easy to reach the equilibrium status. During reaction process, $\mathrm{H}_{2}$ pressure in the reactor was maintained at $5 \pm$ $0.01 \mathrm{MPa}$. As a result, the concentration of $\mathrm{H}_{2}$ can be considered as nearly constant during hydrogenation. Thus, the reaction is assumed to obey a pseudo-first-order kinetic model. ${ }^{40}$ Therefore, the reaction rate equation according to the classical equation is:

$$
r_{\mathrm{i}}=\frac{\mathrm{d} c_{\mathrm{i}}}{\mathrm{d} t}=k_{\mathrm{j}} \times c_{\mathrm{i}}
$$

where $c_{\mathrm{i}}$ is the concentration of each resin acid, $t$ represents to the observation times, and $k_{\mathrm{j}}$ is the reaction rate. Based on the proposed reaction pathway (Fig. 5), $r_{\mathrm{i}}$ for each reaction can be expressed as follows:

$$
\begin{gathered}
r_{\mathrm{AA}}=\frac{\mathrm{d} C_{\mathrm{AA}}}{\mathrm{d} t}=k_{1} \times C_{\mathrm{NEA}}+k_{2} \times C_{\mathrm{PAA}}-\left(k_{3}+k_{4}\right) C_{\mathrm{AA}} \\
r_{\mathrm{NEA}}=\frac{\mathrm{d} C_{\mathrm{NEA}}}{\mathrm{d} t}=-k_{1} \times C_{\mathrm{NEA}} \\
r_{\mathrm{PAA}}=\frac{\mathrm{d} C_{\mathrm{PAA}}}{\mathrm{d} t}=-k_{2} \times C_{\mathrm{PAA}} \\
r_{\mathrm{DIA}}=\frac{\mathrm{d} C_{\mathrm{DIA}}}{\mathrm{d} t}=k_{3} \times C_{\mathrm{AA}} \\
r_{\mathrm{TEA}}=\frac{\mathrm{d} C_{\mathrm{TEA}}}{\mathrm{d} t}=k_{4} \times C_{\mathrm{AA}}
\end{gathered}
$$




$$
\begin{aligned}
& r_{\mathrm{DEA}}=\frac{\mathrm{d} C_{\mathrm{DEA}}}{\mathrm{d} t}=k_{5} \times C_{\mathrm{DEA}} \\
& r_{\mathrm{PAS}}=\frac{\mathrm{d} C_{\mathrm{PAS}}}{\mathrm{d} t}=-k_{6} \times C_{\mathrm{PAS}}
\end{aligned}
$$

Kinetic studies of rosin hydrogenation were performed under the optimum conditions of a temperature of 423-453 K, $\mathrm{H}_{2}$ pressure of $5 \mathrm{MPa}$, stirring rate of $600 \mathrm{rpm}$, catalyst amount of $5 \mathrm{wt} \%$ and reaction time of $100 \mathrm{~min}$. The experimental concentration of different resin acids over time and the corresponding fitting data are shown in Fig. 6. The rate constants were calculated by the Levenberg-Marquardt nonlinear leastsquares method ${ }^{\mathbf{4 1}}$ and the data were fitted by MATLAB software using a self-written program to obtain the power-type kinetic equations.

Fig. 6 illustrates that the rosin hydrogenation results were fitted well with the first-order kinetic equations (eqn 6(a)-(g)). The reaction rate $(k)$ is a function of temperature; $k$ of each reaction at various temperatures are listed in Table 6.

The activation energies $\left(E_{\mathrm{a}}\right)$ and frequency factors $(A)$ of the reactions were then estimated using Fit2auto software and the Arrhenius equation:

$$
k=A \mathrm{e}^{-E_{\mathrm{a}} / R T}
$$

$E_{\mathrm{a}}$ and $A$ for each reaction and the linear correlation coefficient $\left(R^{2}\right)$ value are listed in Table 6 . All the $R^{2}$ values of the estimated parameters were larger than 0.97 , indicating a close match between the experimental and fitting data and the experiments conducted were sufficient for parameter estimation.

Table 6 reveals that the reaction rate constants at $423-453 \mathrm{~K}$ over the $\mathrm{LDH}-\mathrm{Ni} / \mathrm{Scat}$ catalyst increased with temperature with the order of $k_{6}>k_{1}>k_{3}>k_{2}>k_{4}>k_{5}$. In the disproportionation of rosin over $\mathrm{Pd} / \mathrm{C}, k_{1}$ was smaller than $k_{2}$ with values of 0.0124 and $0.0229 \mathrm{~min}^{-1}$ at $483 \mathrm{~K}$, respectively. ${ }^{24}$ In contrast, in our work, $k_{1}>$ $k_{2}$ and the rate constant of isomerization at $423 \mathrm{~K}\left(0.0211 \mathrm{~min}^{-1}\right)$ was almost twice that of rosin disproportionation, indicating that the LDH-Ni/Scat catalyst has high catalytic activity in not only hydrogenation but also isomerization, especially that of NEA. The rate of NEA isomerization was higher than that of AA hydrogenation, which means hydrogenation can occur continuously. The $k$ value for the generation of DIA $\left(0.0448 \mathrm{~mol} \mathrm{~g}^{-1} \mathrm{~min}^{-1}\right.$ at $\left.453 \mathrm{~K}\right)$ was higher than that of TEA $\left(0.0232 \mathrm{~mol} \mathrm{~g}^{-1} \mathrm{~min}^{-1}\right.$ at $\left.453 \mathrm{~K}\right)$, whereas their corresponding $E_{\mathrm{a}}$ showed the opposite trend (73.02 and $86.67 \mathrm{~kJ} \mathrm{~mol}^{-1}$, respectively), confirming that the generation of DIA has a higher activation rate than that of TEA. Besides, the generation of DIA was faster than that of TEA, consistent with DIA being the main constituent of the HR. Because $k_{5}$ was the smallest observed, the dehydrogenation of AA can be ignored at low temperature, indicating that the $\mathrm{LDH}-\mathrm{Ni} / \mathrm{Scat}$ catalyst possesses high selectivity in rosin hydrogenation.

$E_{\mathrm{a}}$ of the truly kinetically controlled reaction should be higher than $25 \mathrm{~kJ} \mathrm{~mol}^{-1}$. $^{40}$ The smallest $E_{\mathrm{a}}$ of $37.60 \mathrm{~kJ} \mathrm{~mol}^{-1}$ demonstrates that rosin hydrogenation is a kinetically limited reaction. For the isomerization reaction, $E_{\mathrm{a} 1}>E_{\mathrm{a} 2}$, meaning the
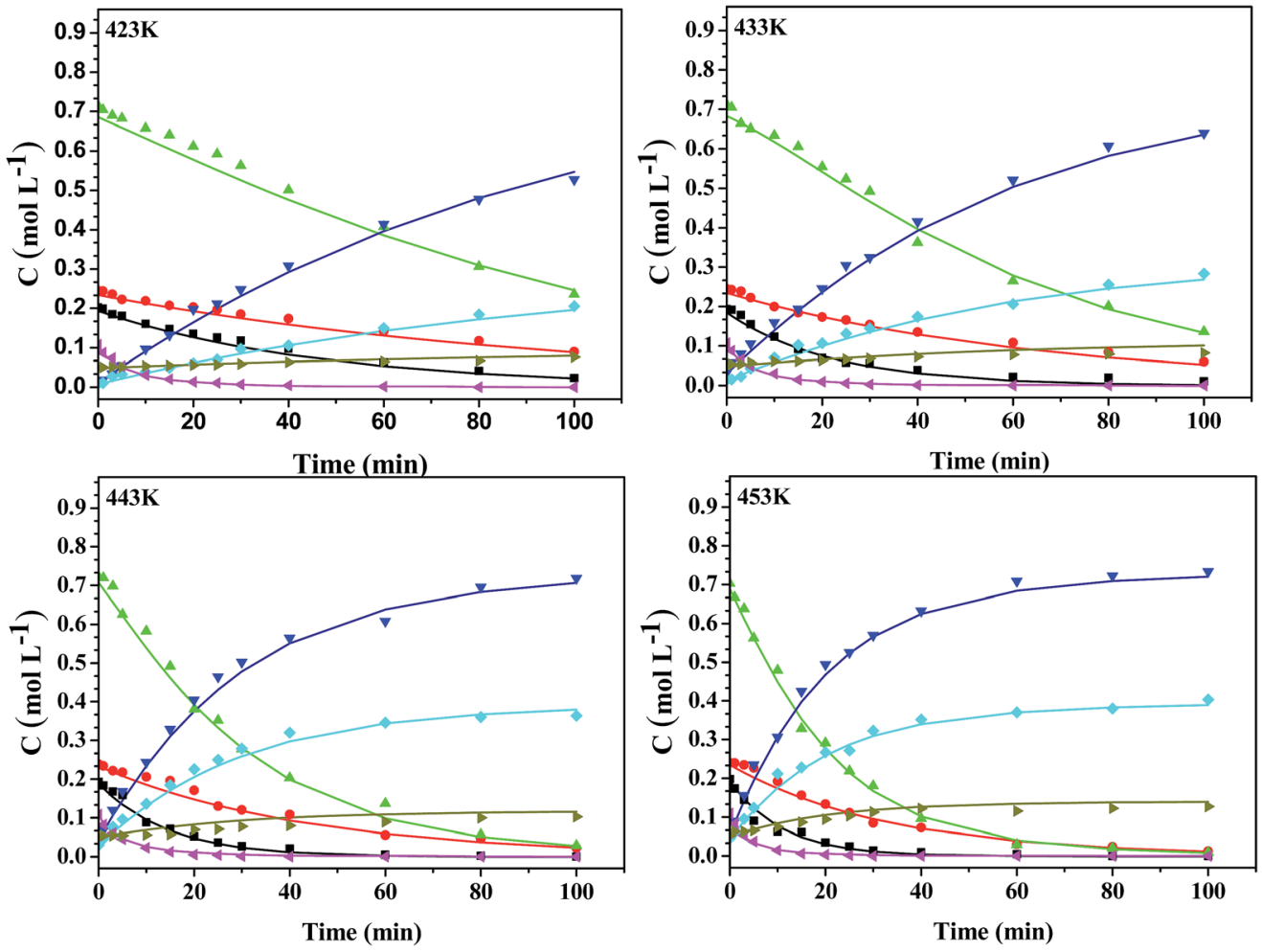

Fig. 6 Comparison of the experimental (data points) and calculated values (line) of the concentrations of resin acids at different temperatures

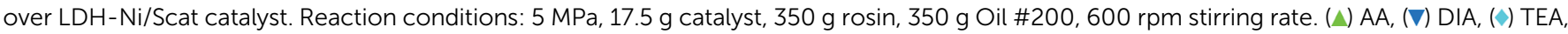
(๑) PAA, ( ) DEA, (ロ) NEA, (ব) PIA. 
Table 6 Kinetic parameters for the catalytic hydrogenation of rosin

\begin{tabular}{|c|c|c|c|c|c|c|c|}
\hline Temperature (K) & \multicolumn{4}{|l|}{ Kinetic constants } & $A\left(\min ^{-1}\right)$ & $E_{\mathrm{a}}\left(\mathrm{kJ} \mathrm{mol}^{-1}\right)$ & $R^{2}$ \\
\hline$k_{2}\left(\min ^{-1}\right)$ & $0.0096 \pm 0.0007$ & $0.0148 \pm 0.0010$ & $0.0228 \pm 0.0029$ & $0.0300 \pm 0.0020$ & $1.51 \times 10^{5}$ & 58.06 & 0.991 \\
\hline$k_{3}\left(\min ^{-1}\right)$ & $0.0121 \pm 0.0002$ & $0.0167 \pm 0.0003$ & $0.0306 \pm 0.0009$ & $0.0448 \pm 0.0008$ & $1.19 \times 10^{7}$ & 73.02 & 0.991 \\
\hline$k_{4}\left(\min ^{-1}\right)$ & $0.0042 \pm 0.0002$ & $0.0070 \pm 0.0002$ & $0.0162 \pm 0.0007$ & $0.0232 \pm 0.0005$ & $2.35 \times 10^{8}$ & 86.67 & 0.973 \\
\hline
\end{tabular}

isomerization of NEA becomes more important as the temperature rises. $E_{\mathrm{a}}$ of AA dehydrogenation is the largest value obtained here. As such, the dehydrogenation reaction is favoured at high temperature and the amounts of DIA and TEA are expected to be at equilibrium when the reaction is conducted at the high end of the temperature range $(453 \mathrm{~K})$. Thus, to obtain large amounts of hydrogenated product, the reaction should be carried out at relatively low temperature. This finding is in line with our previous work, ${ }^{19}$ in which we found that the optimal temperature for rosin hydrogenation over the LDH-Ni/Scat catalyst was the relatively low temperature of $434 \mathrm{~K}$, indicating that this catalyst has high selectivity. $E_{\mathrm{a} 3}$ and $E_{\mathrm{a} 4}$ were higher than $E_{\mathrm{a} 1}$ and $E_{\mathrm{a} 2}$, which indicates that the generation of DIA will be promoted as the reaction temperature rises. The high $k$ $\left(0.9332 \mathrm{~mol} \mathrm{~g}^{-1} \mathrm{~min}^{-1}\right.$ at $\left.453 \mathrm{~K}\right)$ and low $E_{\mathrm{a}}\left(37.60 \mathrm{~kJ} \mathrm{~mol}^{-1}\right)$ obtained here shows that all the PIAs are hydrogenated to PIAs, because of the hydrogenation of the exocyclic double bonds is favored both thermodynamically and kinetically.

Wei et al. ${ }^{42}$ studied the kinetic parameters of rosin hydrogenation on $\mathrm{Pd} / \mathrm{C}$ catalyst at different temperatures in the range of 403-443 K. Activation energies for DIA and TEA generation over the $\mathrm{Pd} / \mathrm{C}$ catalysts were 27.758 and $237.12 \mathrm{~kJ} \mathrm{~mol}^{-1}$, respectively. In this paper, activation energies for the DIA and TEA generation were 86.67 and $107.42 \mathrm{~kJ} \mathrm{~mol}^{-1}$, respectively. The varying activation energy indicates that the $\mathrm{Pd} / \mathrm{C}$ catalyst presents a higher activity in the generation of DIA, while LDH-Ni/Scat fovers the generation of TEA. However, the conversions of AA were almost similar with both of these two catalysts. Due to the environmental benefit (as we used largest industrial solid waste as support) and low-cost, LDH-Ni/Scat catalyst might be a good alternative to the $\mathrm{Pd} / \mathrm{C}$ catalyst in the industrial production of $\mathrm{HR}$.

\subsection{Model examination}

A good fit of the kinetic parameters would confirm the suitability of the mathematical model to describe the reaction.

Table 7 Statistical test for the model of rosin hydrogenation

\begin{tabular}{llll}
\hline Temperature $/ \mathrm{K}$ & $R^{2}$ & $Q$ & $F$ \\
\hline 423 & 0.9996 & $2.67 \times 10^{-3}$ & 3589.929 \\
433 & 0.9831 & $4.15 \times 10^{-3}$ & 2741.335 \\
443 & 0.9798 & $6.50 \times 10^{-3}$ & 2051.807 \\
453 & 0.9991 & $1.75 \times 10^{-3}$ & 6264.077
\end{tabular}

Fig. 6 and Table 6 show that the model satisfactorily described the hydrogenation kinetics for the configuration of a highpressure bath reactor. A statistical $F$-test was performed with a confidence interval of $95 \%{ }^{43}$ The statistical significance of the model can be proved when $F>F(\mathrm{~m}, N-\mathrm{m}, 0.95)$, which denotes the $95 \%$ value of the Fisher distribution with $(\mathrm{m}, N-\mathrm{m})$ degrees of freedom. In our case, $m$ was the number of model parameters, 5 ; and $N$ was the number of sampling points, 13 . Therefore, the $F(5,8,0.95)$ value was 3.69 . The $F$-test results are presented in Table 7. All the $R^{2}$ values at various temperatures are over 0.95 , the sum of errors $(Q)$ are small $\left(1.75 \times 10^{-3}-6.50 \times 10^{-3}\right)$, and all $F$ values are bigger than ten times $F(5,8,0.95)$, suggesting that the results are statistically significant at the $95 \%$ confidence level.

\section{Conclusions}

An effective sampling method to withdraw high-viscosity solution samples from rosin hydrogenation over an LDH-Ni/Scat under high-pressure conditions was proposed. The intrinsic kinetic parameters for each involved reaction were estimated using the Levenberg-Marquart method and a self-written MATLAB program after eliminating both internal and external diffusion effects. A PH dynamic kinetic model was proposed to fit the experimental data. Rosin hydrogenation followed pseudo-first-order kinetics with $R^{2}>0.97 . E_{\mathrm{a}}$ was of $37.60-$ $107.42 \mathrm{~kJ} \mathrm{~mol}^{-1}$ at temperature of $423-453 \mathrm{~K}$. An $F$-test at the 95\% confidence level illustrated the reliability of the mathematical model, which proved to be a useful tool to examine rosin hydrogenation.

\section{Acknowledgements}

This work was supported by National Natural Science Foundation of China (Grant No. 31560241), Natural Science Foundation of Guangxi Provence (Grant No. 2014GXNSFDA118010), Key Laboratory of Petrochemical Resource Processing and Process Intensification Technology (Grant No. 2016Z002), and Study Abroad Program for Excellent Ph.D. Students of Guangxi Zhuang Autonomous Region.

\section{Notes and references}

1 J. Gutierrez and A. Tercjak, RSC Adv., 2014, 4, 32024. 
2 N. H. Choulis, Dermatological drugs, topical agents, and cosmetics, Elsevier Masson SAS, 2014, vol. 30.

3 H. S. Do, J. H. Park and H. J. Kim, J. Appl. Polym. Sci., 2009, 111, 1172-1176.

4 S. Kumar and S. K. Gupta, Polym. Med., 2013, 43, 45-48.

5 H. Li, T. Liang, Y. Li, X. Lai, X. Ren and X. Zeng, J. Adhes. Sci. Technol., 2015, 29, 2220-2232.

6 K. Zhang, S. Shang, P. Sun, M. Shen and D. Wang, J. Appl. Polym. Sci., 2016, 133, 1-9.

7 F. Du, J. Liu, S. Yu and L. Li, J. Porous Mater., 2008, 15, 613617.

8 H. S. Richard and P. D. Harold, Prepr. Pap.-Am. Chem. Soc., Div. Fuel Chem., 1993, 38, 1140-1146.

9 A. Bernas, T. Salmi, D. Y. Murzin, J. P. Mikkola and M. Rintola, Top. Catal., 2012, 55, 673-679.

10 O. Bayraktar and E. L. Kugler, J. Therm. Anal. Calorim., 2003, 71, 867-874.

11 H. L. Chen, Y. S. Tseng and K. C. Hsu, Cem. Concr. Compos., 2004, 26, 657-664.

12 S. Vasireddy, A. Campos, E. Miamee, A. Adeyiga, R. Armstrong, J. D. Allison and J. J. Spivey, Appl. Catal., A, 2010, 372, 184-190.

13 L. Wang, H. Guo, X. Chen, Q. Chen, X. Wei, Y. Ding and B. Zhu, Catal. Sci. Technol., 2015, 5, 3340-3351.

14 Y. Huang, X. Chen, Y. Deng, D. Zhou and L. Wang, Chem. Eng. J., 2015, 269, 434-443.

15 X. Zhang, N. Wang, Y. Xu, Y. Yin and S. Shang, Catal. Commun., 2014, 45, 11-15.

16 J. Jiang, A. Zhang, L. Li and L. Ai, J. Power Sources, 2015, 278, 445-451.

17 Y. Vlamidis, E. Scavetta, M. Gazzano and D. Tonelli, Electrochim. Acta, 2016, 188, 653-660.

18 Z. Tian, Q. Li, J. Hou, L. Pei, Y. Li and S. Ai, J. Catal., 2015, 331, 193-202.

19 Y. Huang, L. Wang, X. Chen, Q. Xie, P. Gan, X. Wei and J. Liang, J. Taiwan Inst. Chem. Eng., 2016, 60, 229-235.

20 A. Srifa, N. Viriya-empikul, S. Assabumrungrat and K. Faungnawakij, Catal. Sci. Technol., 2015, 5, 3693.

21 M. Gabrovska, R. Edreva-Kardjieva, D. Crişan, P. Tzvetkov, M. Shopska and I. Shtereva, React. Kinet., Mech. Catal., 2011, 105, 79-99.

22 L. Zhang, D. Lu, Y. Chen, Y. Tang and T. Lu, J. Mater. Chem. A, 2014, 1252-1256.
23 L. Mckeon, F. Regan, B. Burns and R. Leonard, J. Sep. Sci., 2014, 37, 2791-2796.

24 L. Wang, X. Chen, J. Liang, Y. Chen, X. Pu and Z. Tong, Chem. Eng. J., 2009, 152, 242-250.

25 J. C. Souto, P. Yustos, M. Ladero and F. Garcia-Ochoa, Bioresour. Technol., 2011, 102, 3504-3511.

26 M. Belgacem and A. Gandini, Monomers, Polymers and Composites from Renewable Resources, 2008.

27 Z.-Q. Song, E. Zavarin and D. F. Zinkel, J. Wood Chem. Technol., 1985, 5, 535-542.

28 J. Hagen, Industrial Catalysis: A Practical Approach: Second Edition, 2015.

29 Y. Li, X. Zhang, Q. Zhang, J. Zheng, N. Zhang, B. H. Chen and K. J. Smith, RSC Adv., 2016, 6, 29371-29377.

30 R. J. D. Mark and E. Davis, Fundamentals of Chemical Reaction Engineering, 2013, pp. 184-239.

31 V. K. S. Pappu, V. Kanyi, A. Santhanakrishnan, C. T. Lira and D. J. Miller, Bioresour. Technol., 2013, 130, 793-797.

32 H. S. Fogler, Elements of chemical reaction engineering, 2010, vol. 42.

33 33R. Sitaraman, S. H. Ibrahim and N. R. Kuloor, J. Chem. Eng. Data, 1963, 8, 198-201.

34 34G. E. Totten, S. R. Westbrook and R. J. Shah, in Fuels and lubricants handbook: technology, properties, performance, and testing, 2003, vol. 1, ch. 5.

35 35Y. Dong, F. J. Keil, O. Korup, F. Rosowski and R. Horn, Chem. Eng. Sci., 2016, 142, 299-309.

36 36P. N. Dange, A. Sharma and V. K. Rathod, Catal. Lett., 2014, 144, 1537-1546.

37 37B. Giorgio, F. Inzoli, T. Ziegenhein and D. Lucas, Chem. Eng. Sci., 2017, 160, 144-160.

38 38A. F. Trasarti, N. M. Bertero, C. R. Apesteguía and A. J. Marchi, Appl. Catal., A, 2014, 475, 282-291.

39 39X. Chen, L. Wang, C. Yang, D. Zhang and Z. Tong, J. Chem. Eng. Chin. Univ., 2003, 17, 325-329.

40 40A. Talebian-Kiakalaieh, N. A. S. Amin, A. Zarei and I. Noshadi, Appl. Energy, 2013, 102, 283-292.

41 410. Nelles, Nonlinear system identification: from classical approaches to neural networks and fuzzy models, 2001.

42 42X. Wei, Q. Li, X. Chen, C. Yang, L. Wang and L. Zhou, J. Chem. Eng. Chin. Univ., 2011, 25, 269-274.

43 43S. M. De Lima, B. F. A. Silva, D. V. Pontes, C. F. Pereira, L. Stragevitch and M. F. Pimentel, Fuel, 2014, 115, 46-53. 